\title{
Controle de Plantas daninhas através da Palha de Cana-de- AÇÚCAR Associada À Mistura dos Herbicidas Trifloxysulfuron SODIUM + AMETRINA ${ }^{1}$
}

\author{
Weed Control Through Green Cane Harvesting Residue Combined With the Herbicide Mixture \\ Trifloxysulfuron Sodium + Ametryne
}

GRAVENA, R. ${ }^{2}$, RODRIGUES, J.P.R.G. ${ }^{3}$, SPINDOLA, W. ${ }^{4}$, PITELLI, R.A. ${ }^{5}$ e ALVES, P.L.C.A. ${ }^{5}$

\begin{abstract}
RESUMO - O objetivo deste trabalho foi avaliar os efeitos da palha de cana-de-açúcar resultante da colheita sem queima e da mistura comercial dos herbicidas trifloxysulfuron sodium + ametrina, na emergência e no acúmulo de biomassa seca de nove espécies de plantas daninhas. Os tratamentos foram distribuídos em esquema fatorial $3 \times 3$, sendo três quantidades de palha resultantes da colheita da cana-de-açúcar sem queima $(0,10$ e $15 \mathrm{t} \mathrm{ha}^{-1}$ ), e três doses da mistura formulada dos herbicidas trifloxysulfuron sodium + ametrina $\left(0,1,75\right.$ e 2,00 $\left.\mathrm{kg} \mathrm{ha}^{-1}\right)$, aplicados em condições de pós-emergência das plantas daninhas. As densidades das plantas daninhas foram avaliadas aos 15, 60 e 90 dias após a aplicação (DAA) da mistura dos herbicidas, e a biomassa seca das plantas daninhas, aos 90 DAA. A presença de palha sobre o solo suprimiu as densidades das populações de Brachiaria plantaginea, Digitaria horizontalis, Panicum maximum, Sida glaziovii e Amaranthus hybridus a níveis de infestação considerados satisfatórios de controle. A palhada também reduziu as populações de Senna obtusifolia, Ipomoea hederifolia, I. grandifolia e I. nil, porém em níveis insatisfatórios de controle. A mistura de herbicidas nas doses estudadas controlou todas as espécies de plantas daninhas avaliadas. Na presença da palha, o controle das plantas de S. obtusifolia, I. nil, I. hederifolia e I. grandifolia somente foi satisfatório quando foi aplicada a mistura de herbicidas. Para o controle de P. maximum, houve vantagem na integração dos dois métodos de controle, em relação à aplicação isolada da menor quantidade de palha estudada ou à aplicação da mistura de herbicidas.
\end{abstract}

Palavras-chave: Saccharum spp., cobertura morta, controle químico.

\begin{abstract}
This work aimed to evaluate the effects of green cane harvesting residue and of the herbicide mixture trifloxysulfuron sodium + ametryne on the emergence and dry biomass accumulation of nine weed species. The treatments were arranged in a $3 \times 3$ factorial design, with three green cane harvesting residue amounts $\left(0,10\right.$ and $\left.15 \mathrm{th} \mathrm{h}^{-1}\right)$ and three rates of the commercial formulation of the herbicide mixture trifloxysulfuron sodium + ametryne $\left(0,1.75\right.$ and $\left.2.00 \mathrm{~kg} \mathrm{ha}^{-1}\right)$, applied under weed post-emergence conditions. Weed density was evaluated at 15, 60 and 90 days after herbicide application (DAA) and weed dry biomass at 90 DAA. The presence of the green cane harvesting residue on the soil suppressed the density of the populations of Brachiaria plantaginea, Digitaria horizontalis, Panicum maximum, Sida glaziovii and Amaranthus hybridus. The green cane harvesting residue reduced the populations of Senna obtusifolia, Ipomoea hederifolia, I. grandifolia and I. nil, even though the control was not satisfactory. The herbicide mixture studied controlled all the weed species evaluated. In the presence of green cane harvesting residue, the control of S. obtusifolia, I. nil, I. hederifolia and I. grandifolia was satisfactory only when the herbicide mixture was applied.Green cane harvesting residue combined with the herbicide mixture was advantageous for $\boldsymbol{P}$. maximum control, compared with applying the smallest amount of green cane harvesting residue or the herbicide mixture alone on the soil surface.
\end{abstract}

Key words: Saccharum spp., mulching, chemical control.

Recebido para publicação em 11.10.2002 e na forma revisada em 10.9.2004.

Eng.-Agr., Doutorando em Fitotecnia, Dep. de Produção Vegetal da Escola Superior de Agricultura “Luiz de Queiroz" - ESALQ/ USP, Caixa Postal 09, 13418-900 Piracicaba-SP. ${ }^{3}$ Eng.-Agrônomo. ${ }^{4}$ Técnico Agrícola. ${ }^{5}$ Prof. Dr., Dep. de Biol. Aplicada à Agropecuária, FCAV/UNESP, Via de Acesso Prof. Paulo D. Castellane, s/n, 14884-900 Jaboticabal-SP. 


\section{INTRODUÇÃO}

A área de produção da cana-de-açúcar destinada à colheita mecanizada da cana-crua tem crescido nas últimas décadas. A adoção desse sistema de colheita tem resultado em importantes modificações nas técnicas de cultivo, como o uso de maiores espaçamentos e a deposição de palha sobre o solo, que influenciam diretamente a ocorrência e o manejo de plantas daninhas (Velini \& Negrissoli, 2000).

A interferência das coberturas mortas, geradas pela deposição da palha, nas composições específicas das comunidades infestantes é atribuída fundamentalmente aos efeitos físicos e amensais. Os efeitos físicos referem-se às alterações nas amplitudes das variações térmicas e hídricas do solo e à filtragem da luz que atinge a palhada, afetando a dormência e, conseqüentemente, a germinação das plantas daninhas (Taylorson \& Borthwick, 1969; Fener, 1980; Egley \& Duke, 1985). Os efeitos amensais devem-se à liberação de compostos aleloquímicos, que afetam, de forma direta ou indireta, a germinação, o crescimento e o desenvolvimento de algumas plantas daninhas (Rice, 1984; Pitelli, 1985). De acordo com as características desses efeitos, proporcionados pela cobertura morta, é possivel considerarse que a composição da flora infestante e a eficiência do seu controle pela cobertura morta são influenciadas pela quantidade, pela composição, pela periodicidade de produção e pelo tempo de permanência da cobertura morta em uma determinada área.

Estudos realizados por diferentes autores demonstraram que algumas espécies de plantas daninhas, predominantes na cultura de cana-de-açúcar, apresentam comportamento diferenciado em função da quantidade de palha depositada sobre o solo (Velini et al., 2000; Martins et al., 1999; Medina Melendez, 1990). Plantas daninhas normalmente consideradas importantes nessa cultura, como Brachiaria decumbens, B. plantaginea, Panicum maximum e Digitaria horizontalis, podem ser eficientemente controladas pela presença de $15 \mathrm{t} \mathrm{ha}^{-1}$ de palha (Velini et al., 2000). O mesmo não ocorre com Ipomoea grandifolia e Euphorbia heterophylla, cujo controle pela palha é deficiente (Martins et al., 1999).
As espécies menos afetadas pela presença da palha podem ser selecionadas com o tempo, tornando-se importantes problemas nos canaviais. Portanto, estudos sobre seleção da flora infestante pela palha são importantes, pois permitem identificar espécies com potencial de seleção no sistema de colheita de canacrua e estabelecer programas de controle preventivo. Ademais, é de igual importância o desenvolvimento de métodos eficientes para o manejo dessas plantas daninhas pouco sensíveis ao controle pela palha, caso ocorram em elevadas densidades na lavoura.

O objetivo deste trabalho foi avaliar a eficiência da palha de cana-de-açúcar e da mistura comercial dos herbicidas trifloxysulfuron sodium e ametrina no controle de plantas daninhas que ocorrem em canaviais.

\section{MATERIAL E MÉTODOS}

O experimento foi realizado em Jaboticabal-SP, entre dezembro de 2000 e março de 2001. As parcelas experimentais foram delimitadas lateralmente por paredes de alvenaria com $30 \mathrm{~cm}$ de profundidade e $15 \mathrm{~cm}$ de altura, com uma área de $1,44 \mathrm{~m}^{2}$, e preenchidas com terra coletada na camada superficial de um solo (LVE) sem resíduos de herbicida. As análises física e química do solo mostraram as seguintes características: textura argilosa; $\mathrm{pH} \mathrm{em} \mathrm{CaCl}_{2}$ de 5,9; $20 \mathrm{~g} \mathrm{dm}^{-3}$ de matéria orgânica; $45 \mathrm{mg} \mathrm{dm}^{-3}$ de $\mathrm{P}$, em resina; e teores de $\mathrm{K}, \mathrm{Ca}, \mathrm{Mg}$ e $\mathrm{H}+\mathrm{Al}$ de 3,1, 46,31 e $25 \mathrm{mmol}_{\mathrm{c}} \mathrm{dm}^{-3}$, respectivamente. A área útil de cada parcela experimental $\left(0,75 \mathrm{~m}^{2}\right)$ foi subdividida em nove parcelas menores (de 50 x 16,7 cm), com o objetivo de facilitar a identificação das diferentes espécies de plantas daninhas semeadas.

Procedeu-se, então, em cada parcela, à semeadura de Panicum maximum, Brachiaria plantaginea, Digitaria horizontalis, Senna obtusifolia, Sida glaziovii, Amaranthus hybridus, Ipomoea nill, I. hederifolia e I. grandifolia, distribuindo-se, nas subparcelas, cada espécie separadamente. O número de sementes, por espécie, foi de 200.

O delineamento experimental foi em blocos casualizados, com três repetições, com os tratamentos dispostos no esquema fatorial $3 \times 3$, sendo três quantidades de palha 
de cana-de-açúcar $\left(0,10\right.$ e $\left.15 \mathrm{t} \mathrm{ha}^{-1}\right)$ e três doses da mistura comercial dos herbicidas trifloxysulfuron sodium e ametrina $(0,1,75$ e $2,00 \mathrm{~kg} \mathrm{ha}^{-1}$ ), aplicadas em pós-emergência. A palha de cana-de-açúcar, variedade SP81816, foi obtida de uma área comercial recémcolhida e depositada nas parcelas, no mesmo dia em que foram semeadas as plantas daninhas.

A aplicação da mistura de herbicidas foi realizada quando as plantas daninhas apresentavam entre duas e quatro folhas verdadeiras (21 dias após a semeadura), utilizando-se de um pulverizador costal, pressurizado a $\mathrm{CO}^{2}$, mantido à pressão constante de $280 \mathrm{kPa}$, com bicos leque, XR 110.02, calibrado para aplicar o equivalente a $200 \mathrm{~L} \mathrm{ha}^{-1} \mathrm{de}$ calda. Por ocasião da aplicação, as temperaturas do ar e do solo eram de 25,0 e $24,6{ }^{\circ} \mathrm{C}$, respectivamente; a umidade relativa do ar era de $92 \%$ e o solo estava úmido.

O número de plantas daninhas sobreviventes foi avaliado aos 15, 60 e 90 dias após a aplicação (DAA) da mistura de herbicidas. Aos 90 DAA, também foi obtida a biomassa seca acumulada pelas diferentes populações de plantas daninhas.

Os resultados foram submetidos à análise de variância e as médias comparadas pelo teste de Tukey a $5 \%$ de probabilidade. Os dados foram previamente transformados em raiz quadrada de $(\mathrm{x}+1)$, com o objetivo de proporcionar a distribuição normal dos dados.

\section{RESULTADOS E DISCUSSÃO}

$\mathrm{Na}$ maioria das avaliações houve efeito significativo da interação entre os fatores em estudo (quantidade de palha e dose de herbicida) e, portanto, nas figuras, estão apresentados os resultados obtidos no desdobramento da interação. Nas avaliações nas quais não houve significância da interação estão apresentados os resultados obtidos para os efeitos principais dos tratamentos.

A aplicação isolada da palha da cana-deaçúcar (10 ou $15 \mathrm{t} \mathrm{ha}^{-1}$ ) ou da mistura dos herbicidas trifloxysulfuron sodium e ametrina ( 1,75 ou $\left.2,00 \mathrm{~kg} \mathrm{ha}^{-1}\right)$ praticamente promoveu o controle total de B. plantaginea (Figura 1). Dessa forma, na presença das quantidades de palha testadas, não é necessário o uso de herbicidas para o controle dessa planta daninha. $\mathrm{O}$ decréscimo no número de plantas, que foi observado ao longo do período experimental, no tratamento sem controle das plantas daninhas, pode ser atribuído à mortalidade proporcionada pela competição entre plantas, que se intensificou com o crescimento. Comportamento similar foi observado para $D$. horizontalis (dados não apresentados).

O comportamento das plantas de $P$. maximum diferiu daquele das demais monocotiledôneas. Até os 60 DAA, a presença de 10 tha $^{-1}$ de palha, sem aplicação da mistura de herbicidas, reduziu o número de plantas de $P$. maximum em $67 \%$ (Figura 2). Por outro lado, $15 \mathrm{t} \mathrm{ha}^{-1}$ de palha promoveram o controle total dessa planta daninha. A aplicação isolada da mistura de herbicidas controlou mais de $80 \%$ das plantas de $P$. maximum. Na presença de $10 \mathrm{t} \mathrm{ha}^{-1}$ de palha constatou-se ganho em eficiência quando houve a integração com o controle químico (Figura 2).

Aos 90 DAA, considerando o número de plantas sobreviventes de $P$. maximum, não foi significativa a interação entre as aplicações da mistura de herbicidas e da palha, sendo apresentados somente os efeitos principais dos tratamentos. No entanto, houve efeito significativo da interação para o acúmulo de biomassa seca (Figura 2). Analisando os resultados de biomassa seca, confirmou-se que a quantidade de $10 \mathrm{t} \mathrm{ha}^{-1}$ de palha, sem herbicida, foi menos eficiente no controle que $15 \mathrm{t} \mathrm{ha}^{-1}$ de palha, uma vez que causou reduções no crescimento das populações de $P$. maximum em 86 e $100 \%$, respectivamente. A aplicação isolada da mistura de herbicidas proporcionou reduções na biomassa seca superiores a 90\%. Guando na presença de $10 \mathrm{t} \mathrm{ha}^{-1}$ de palha, houve ganho em eficiência com a aplicação do controle químico, confirmando a vantagem na integração da palha com a mistura de herbicidas.

Em relação ao efeito da palha de cana-deaçúcar sobre a emergência de plantas daninhas monocotiledôneas, Velini et al. (2000) observaram que o aumento da quantidade de palha pode reduzir a emergência de plantas de $B$. plantaginea, $B$. decumbens, $D$. horizontalis e P. maximum. A presença de $15 \mathrm{t} \mathrm{ha}^{-1}$ de palha pode suprimir totalmente a emergência dessas

Planta Daninha, Viçosa-MG, v. 22, n. 3, p. 419-427, 2004 
espécies, e $10 \mathrm{t} \mathrm{ha}^{-1}$ também podem inibir a emergência de $D$. horizontalis. Medeiros (2001), estudando essas mesmas quatro espécies de monocotiledôneas, na presença de $15 \mathrm{t} \mathrm{ha}^{-1}$ de palha de cana-de-açúcar, também observou intensa supressão da emergência das plantas. Esses resultados são semelhantes aos obtidos no presente estudo e confirmam observações de campo, que constatam redução na incidência dessas plantas daninhas nas áreas de cana-crua. Entretanto, em áreas com desuniformidade na deposição da palha é possivel a ocorrência de algumas dessas plantas daninhas, especialmente de $P$. maximum, podendo exigir a adoção de práticas de controle.
A palha da cana-de-açúcar (10 ou $\left.15 \mathrm{t} \mathrm{ha}^{-1}\right)$ ou o herbicida ( 1,75 ou $\left.2,00 \mathrm{~kg} \mathrm{ha}^{-1}\right)$, aplicados isoladamente, controlaram totalmente as plantas de A. hybridus (Figura 3). Dessa forma, na presença das quantidades testadas de palha, o uso de herbicidas para o controle dessa espécie pode ser desnecessário, não havendo vantagem na integração dos dois métodos de controle. Os resultados obtidos para S. glaziovii foram parecidos, pois não ocorreram diferenças significativas entre os tratamentos com controle das plantas daninhas, embora a presença de $10 \mathrm{t} \mathrm{ha}^{-1}$ de cobertura morta não tenha eliminado totalmente a população de S. glaziovii (dados não apresentados).
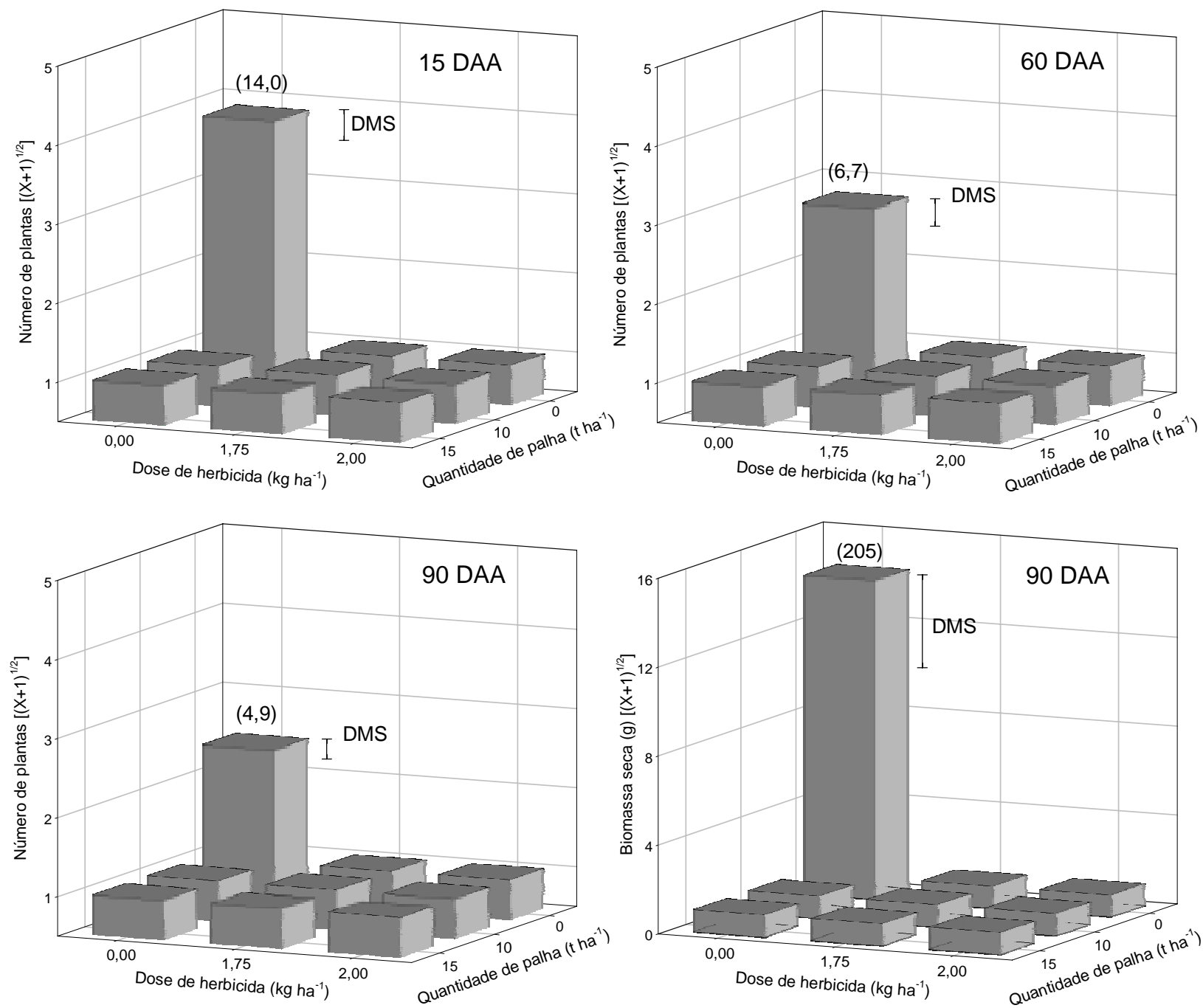

Figura 1 - Efeito da palha de cana-de-açúcar e da mistura dos herbicidas trifloxysulfuron sodium e ametrina no número de plantas e na biomassa seca de Brachiaria plantaginea em diferentes épocas após a aplicação da mistura de herbicidas. Os valores reais observados estão apresentados entre parênteses. (DMS = diferença mínima significativa: $\mathrm{P}<0,05)$. 

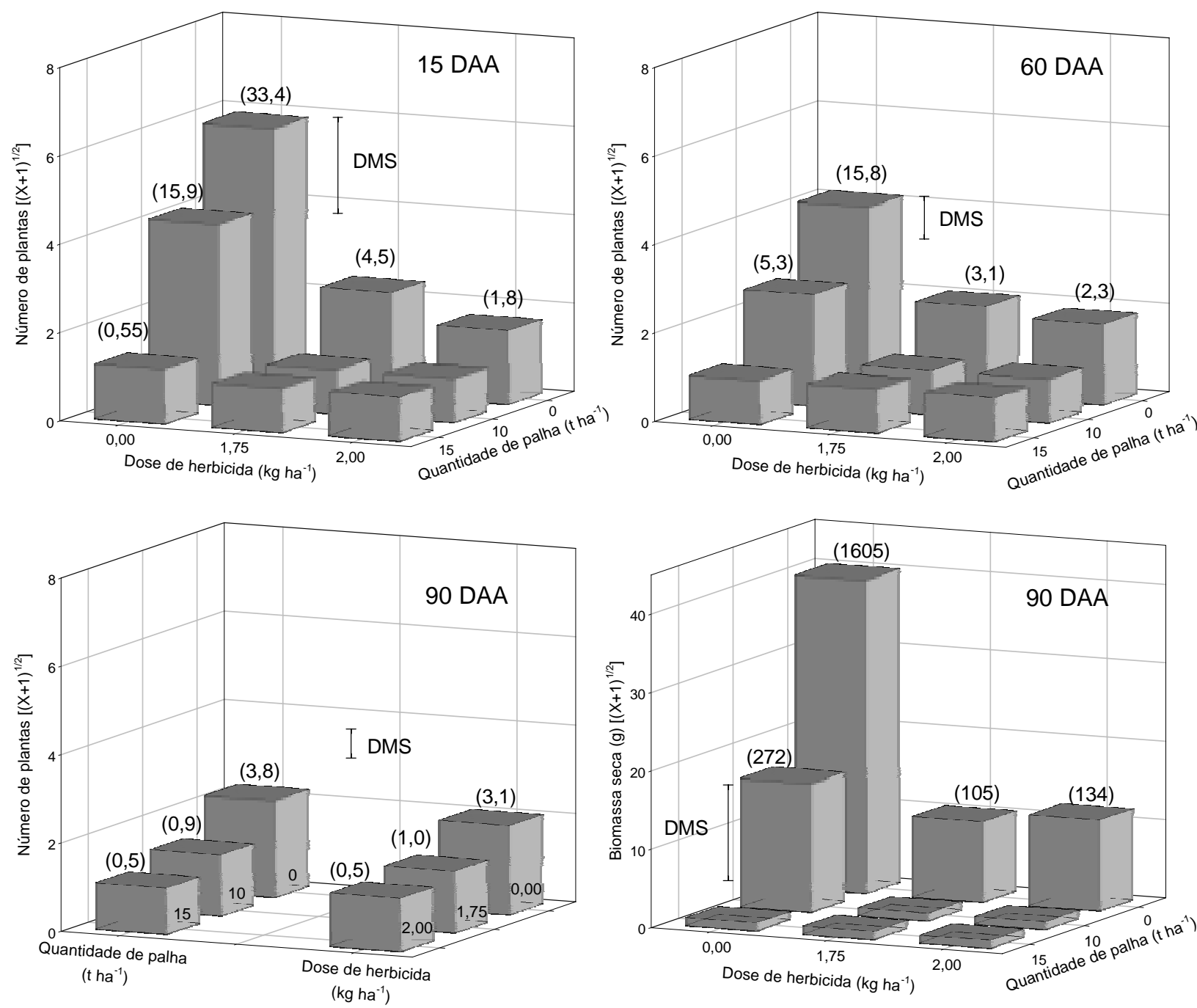

Figura 2 - Efeito da palha de cana-de-açúcar e da mistura dos herbicidas trifloxysulfuron sodium e ametrina no número de plantas e na biomassa seca de Panicum maximum em diferentes épocas após a aplicação da mistura de herbicidas. Os valores reais observados estão apresentados entre parênteses. (DMS = diferença mínima significativa: $\mathrm{P}<0,05)$.

S. obtusifolia e as espécies de Ipomoea foram as plantas daninhas menos afetadas pela palha da cana-de-açúcar. S. obtusifolia não sofreu qualquer interferência da cobertura morta (Figura 4). As diferentes espécies de Ipomoea tiveram comportamento semelhante entre si; constatou-se redução em suas populações, principalmente devido à maior quantidade de palha, aos 15 e 60 DAA (Figura 5). As reduções proporcionadas por $15 \mathrm{t} \mathrm{ha}^{-1}$, em relação à ausência da palha, foram de $62 \mathrm{e}$ $53 \%$, aos 15 e 60 DAA, respectivamente. O acúmulo de biomassa seca pelas plantas de Ipomoea foi maior na presença da palha (Figura 5). Esse resultado provavelmente ocorreu em virtude da intensa competição entre as plantas que cresceram sem a presença da palha, que foi onde houve maior número total de plantas emergidas e maior acúmulo total de biomassa seca.

Considerando os tratamentos com herbicida, observou-se que S. obtusifolia e as espécies de Ipomoea, independentemente da presença ou ausência da palha, foram eficientemente controladas pela aplicação da mistura 

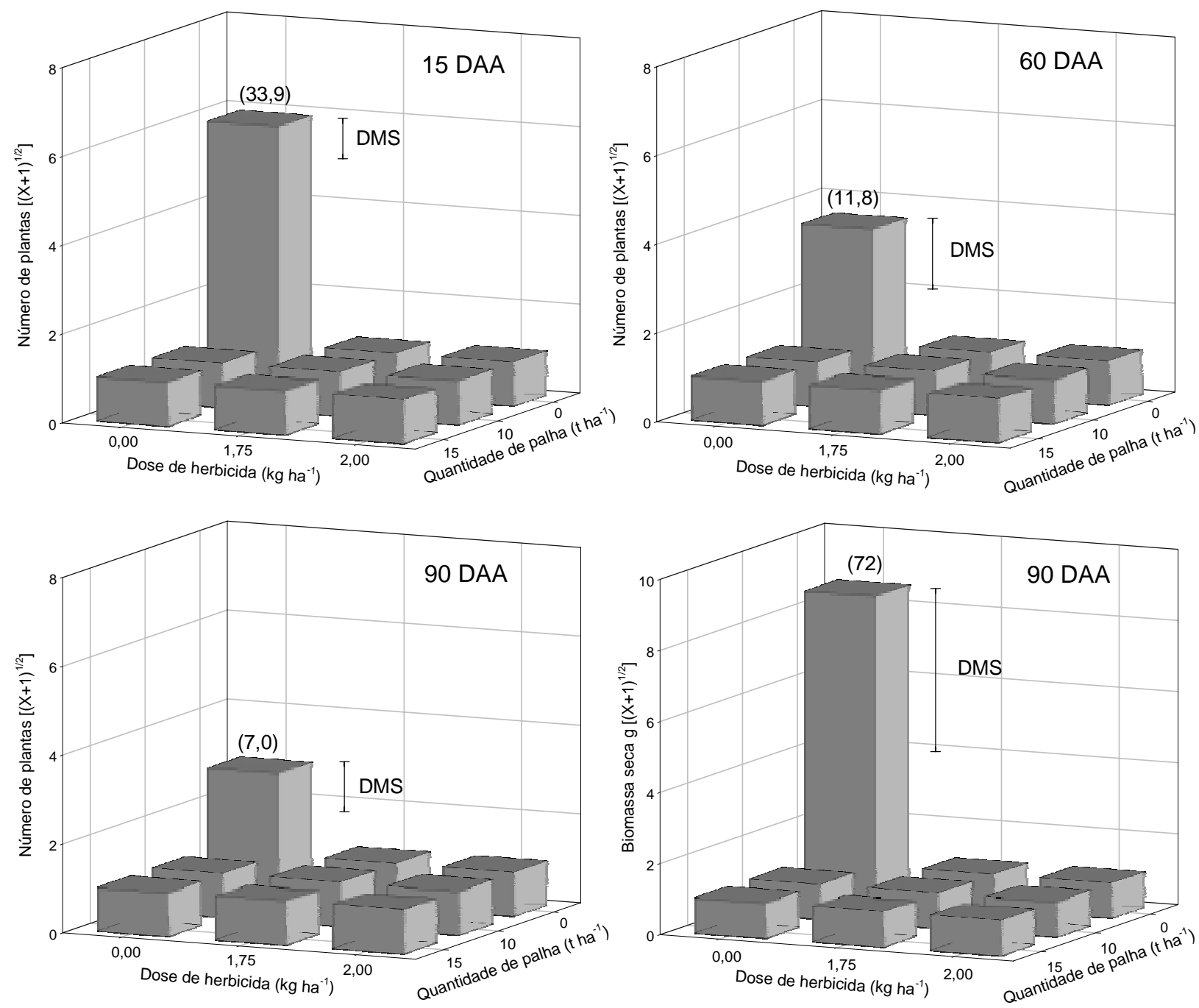

Figura 3 - Efeito da palha de cana-de-açúcar e da mistura dos herbicidas trifloxysulfuron sodium e ametrina no número de plantas e na biomassa seca de Amaranthus hybridus em diferentes épocas após a aplicação da mistura de herbicidas. Os valores reais observados estão apresentados entre parênteses. (DMS = diferença mínima significativa: $\mathrm{P}<0,05)$.

de herbicidas. Isso resultou em valores muito baixos para o número de plantas e para a biomassa seca acumulada, com reduções superiores a 97\%, em relação aos tratamentos sem aplicação da mistura de herbicidas.

Teem et al. (1980) observaram que as sementes de $S$. obtusifolia possuem capacidade de emergir em profundidades de até $12,7 \mathrm{~cm}$. Isso pode explicar os resultados obtidos no presente trabalho, em que, mesmo com grandes quantidades de palha sobre o solo, as plantas de S. obtusifolia foram capazes de emergir, tornando-se necessário o controle dessa planta daninha em áreas de cana-crua.
Martins et al. (1999), avaliando a interferência da palha da cana-de-açúcar na germinação de plantas daninhas dicotiledôneas, observaram que a emergência de Sida rhombifolia decresceu com o aumento da quantidade de palha sobre o solo, até $15 \mathrm{t} \mathrm{ha}^{-1}$; que I. grandifolia e Bidens pilosa apenas sofreram pequena redução na emergência devido à presença dessa quantidade de palha; e que não houve efeito da palha na emergência de Euphorbia heterophylla. Medeiros (2001) obteve resultados parecidos na presença de 15 t ha $^{-1}$ de palha, não constatando inibição na emergência de I. grandifolia e E. heterophylla. 
Azania et al. (2002) determinaram que, com até $15 \mathrm{t} \mathrm{ha}^{-1}$ de palha, a emergência de I. grandifolia, I. hederifolia e I. nil não foi significativamente afetada, tendo sido constatada redução nas populações dessas plantas daninhas somente na presença de $20 \mathrm{t} \mathrm{ha}^{-1}$. Para as espécies Ipomoea quamoclit e Merremia cissoides, o efeito negativo da palha de canade-açúcar foi observado nas quantidades de 15 e 20 t ha $^{-1}$, mas não em quantidade inferior a $10 \mathrm{t} \mathrm{ha}^{-1}$. Os resultados obtidos por esses autores confirmam os do presente estudo e indicam que algumas espécies do gênero Ipomoea tendem a ser bastante problemáticas nas áreas de cana-de-açúcar conduzidas no sistema de colheita mecanizada da cana-crua.

Dentre os vários fatores que podem influenciar a eficiência dos hebicidas residuais, destaca-se, na presença da palha, a capacidade de o herbicida atingir o solo, que pode estar diretamente relacionada à ocorrência de precipitações após a aplicação do produto (Medeiros, 2001). Neste estudo, ocorreram precipitações nos dias subseqüentes à aplicação da mistura comercial dos herbicidas trifloxysulfuron sodium e ametrina, o que favoreceu o excelente efeito residual que se constatou até 90 DAA.
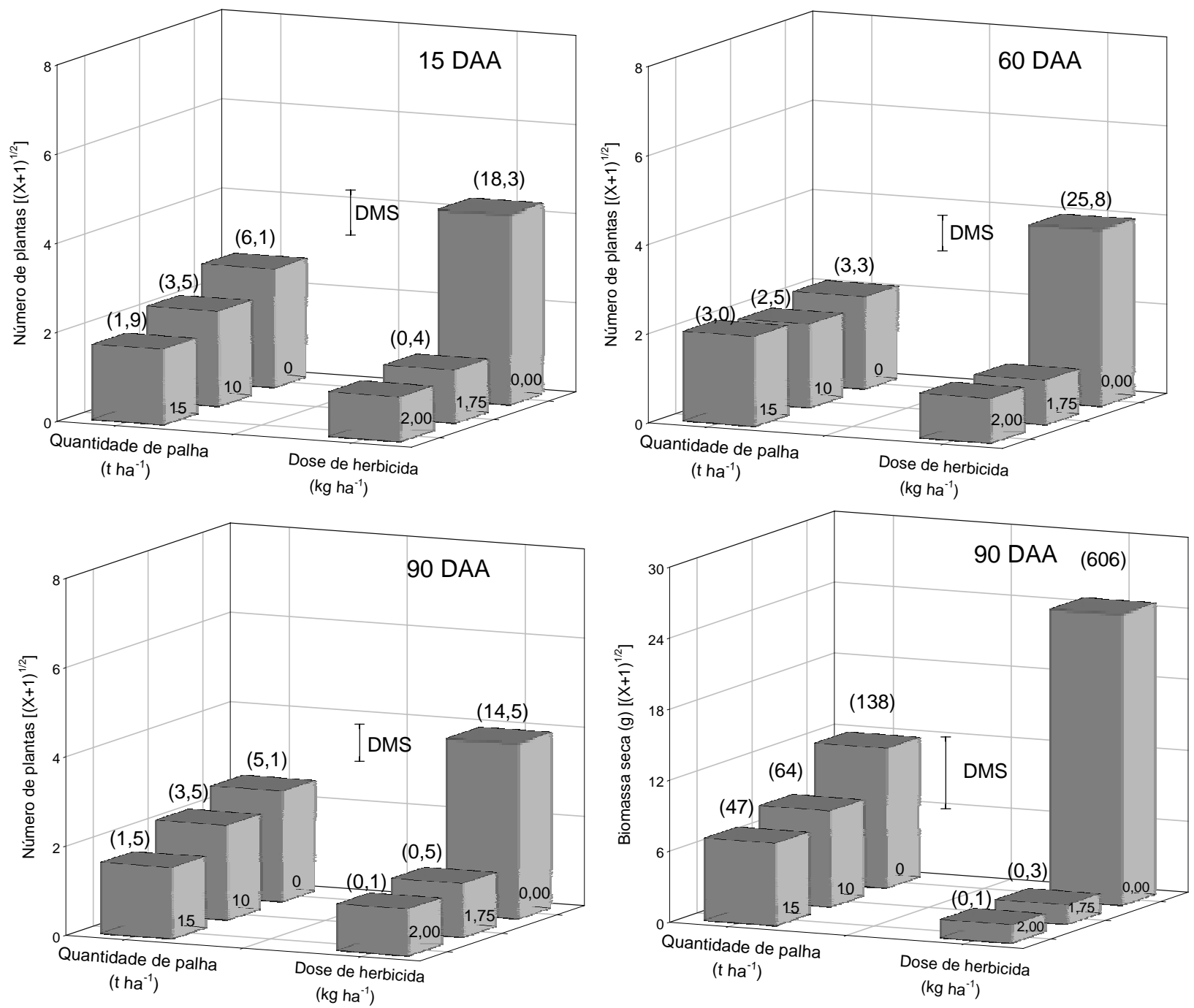

Figura 4 - Efeito da palha de cana-de-açúcar e da mistura dos herbicidas trifloxysulfuron sodium e ametrina no número de plantas e na biomassa seca de Senna obtusifolia em diferentes épocas após a aplicação da mistura de herbicidas. Os valores reais observados estão apresentados entre parênteses. (DMS = diferença mínima significativa: $\mathrm{P}<0,05)$. 

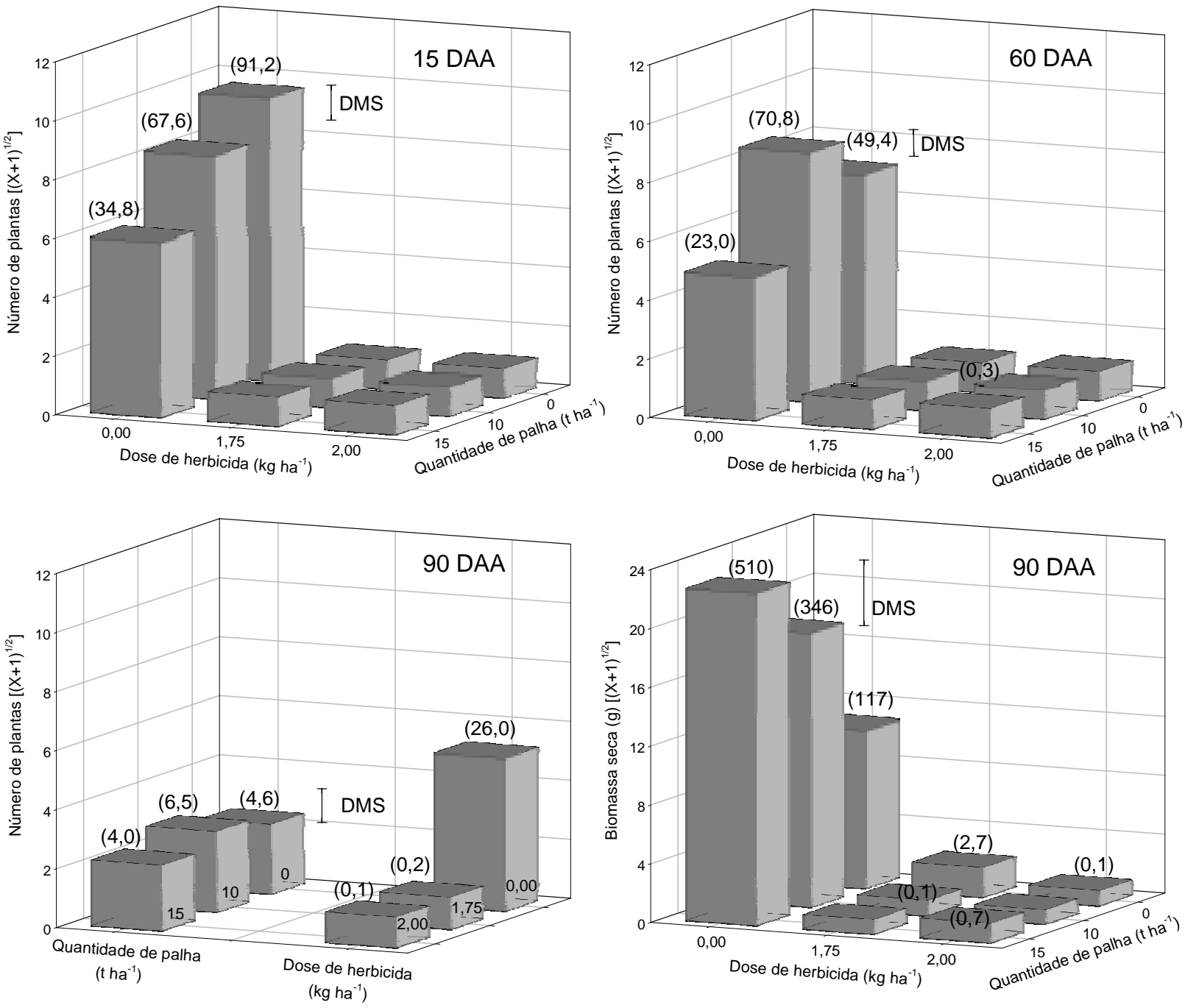

Figura 5 - Efeito da palha de cana-de-açúcar e da mistura dos herbicidas trifloxysulfuron sodium e ametrina no número de plantas e na biomassa seca de Ipomoea spp. em diferentes épocas após a aplicação da mistura de herbicidas. Os valores reais observados estão apresentados entre parênteses. (DMS = diferença mínima significativa: $\mathrm{P}<0,05)$.

\section{LITERATURA CITADA}

AZANIA, A. A. P. M. et al. Interferência da palha de canade-açúcar (Saccharum spp.) na emergência de espécies de plantas daninhas da família convolvulaceae. Planta Daninha, v. 20, n. 2, p. 207-212, 2002.

EGLEY, G. H.; DUKE, S. Physiology of weed seed dormancy and germination. In: DUKE, S. O. Weed Physiology. I. Reproduction and Ecophysiology. Florida: CRC Press, 1985. p. 27-64.

FENER, M. Germination tests of thirty-two East African weed species. Weed Res., v. 20, p. 135-138, 1980.
MARTINS, D. et al. Emergência em campo de dicotiledôneas infestantes em solo coberto com palha de cana-de-açúcar.

Planta Daninha, v. 17, n. 1, p. 151-161, 1999.

MEDEIROS, D. Efeitos da palha de cana-de-açúcar (Saccharum spp.) sobre o manejo de plantas daninhas e dinâmica do banco de sementes. 2001. 126 f.

Dissertação (Mestrado em Fitotecnia) - Escola Superior de Agricultura "Luiz de Queiroz”, Piracicaba, 2001.

MEDINA MELENDEZ, J. A. Efeito da cobertura do solo no controle de plantas daninhas na cultura do pepino (Cucumis sativus L.). 1990. 104 f. Dissertação (Mestrado em Fitotecnia) - Escola Superior de Agricultura "Luiz de Queiroz”, Piracicaba, 1990. 
PITELLI, R. A. Interferência de plantas daninhas em culturas agrícolas. Inf. Agropec., v. 11, n. 129, p. 16-27, 1985.

RICE, E. L. Allelopathy. New York: Academic Press, 1984. $422 \mathrm{p}$.

TAYLORSON, R. B.; BORTHWICK, H. A. Light filtration by foliar canopies: significance for light-controlled weed seed germination. Weed Sci., v. 17, n. 1, p. 48-51, 1969.

TEEM, D. H.; HOVELAND, C. S.; BUCHANAN, G. A. Sicklepod (Cassia obtusifolia) and Coffee senna (Cassia occidentalis): geographic distribution, germination and emergence. Weed Sci., v. 28, n. 1, p. 68-71, 1980.
VELINI, E. D.; NEGRISSOLI, E. Controle de plantas daninhas em cana-crua. In: CONGRESSO BRASILEIRO DA CIÊNCIA DAS PLANTAS DANINHAS, 22., 2000,

Foz do Iguaçu. Anais... Londrina: SBCPD, 2000. p. 148-164.

VELINI, E. D. et al. Efeito da palha da cana-de-açúcar sobre a germinação das principais espécies de plantas daninhas gramíneas desta cultura. In: CONGRESSO BRASILEIRO DA CIÊNCIA DAS PLANTAS DANINHAS, 22., 2000, Foz do Iguaçu. Resumos... Londrina: SBCPD, 2000. p. 15. 